\title{
Smartphone Use and Academic Performance: Correlation or Causal Relationship?
}

By Stijn Baert, i Sunčica Vujić, ii Simon Amez,iii Matteo Claeskens, iv Thomas

Daman,v Arno Maeckelberghe,vi Eddy Omey, vii and Lieven De Marez ${ }^{\text {vii }}$

\footnotetext{
' Ghent University, Research Foundation - Flanders, University of Antwerp, Université catholique de Louvain, IZA, GLO, and IMISCOE. Corresponding author. Postal address: Sint-Pietersplein 6, B-9000 Ghent, Belgium. Telephone number: 003292643481. Email address: Stijn.Baert@UGent.be.

ii University of Antwerp and University of Bath.

iii Ghent University.

iv Ghent University.

$\checkmark$ University of Antwerp.

vi Ghent University.

vii Ghent University.

viii Ghent University and Imec.
} 


\begin{abstract}
After a decade of correlational research, this study attempts to measure the causal impact of (general) smartphone use on educational performance. To this end, we merge survey data on general smartphone use, exogenous predictors of this use, and other drivers of academic success with the exam scores of first-year students at two Belgian universities. The resulting data are analysed with instrumental variable estimation techniques. A one-standard-deviation increase in daily smartphone use yields a decrease in average exam scores of about one point (out of 20). When relying on ordinary least squares estimations, the magnitude of this effect is substantially underestimated. The negative association between smartphone use and exam results is more outspoken for students (i) with highly educated fathers, (ii) with divorced parents and (iii) who are in good health. Policy-makers should at least invest in information and awareness campaigns of teachers and parents to highlight this trade-off between smartphone use and academic performance.
\end{abstract}

Keywords: smartphone use; academic performance; causality. 


\section{This article is forthcoming in Kyklos. Please cite the journal article.}

\section{INTRODUCTION}

Across OECD countries, in recent years, the question of whether or not smartphone use (i.e. the time that an individual is active on her/his smartphone per day or per week) affects performance and quality of life has occupied an important place in social debate (see, e.g., Eliahu, 2014; OECD, 2017; Samuel, 2017). This debate is fuelled by a multidisciplinary scientific literature that not only relates smartphone use to reduced performance during driving, walking, and working, but also to poorer study results (Abouk and Adams, 2013; Andreassen, 2015; Bhargava and Pathania, 2013; Lepp et al., 2013; Levine et al., 2012). Scholars' interest in the connection between smartphone use and the latter outcome (poorer study results) is not surprising. Smartphone use in the OECD region has increased massively during the past decade (Lepp et al., 2015; Vanhaelewyn and De Marez, 2017), such that its potential adverse effect on educational performance may have a major societal impact. In the present study, we contribute to this literature concerning the interplay between (general) smartphone use and educational performance.

There are several theoretical mechanisms that support a causal effect of smartphone use on educational performance. On the one hand, the use of a smartphone may improve the efficiency of students' study activities by allowing them to continuously search for (study-related) information and by facilitating teamwork (Chen and Yan, 2016; Hawi and Samaha, 2016). On the other hand, research has shown that students see their smartphones primarily as sources of entertainment, rather than as study tools (Barkley and Lepp, 2013; Lepp et al., 2013). As a result, a trade-off, in terms of time use à la Becker (1965) between smartphone use and study activities can be expected (Chen and Yan, 2016; Lepp et al., 2015). Apart from this trade-off in time use, there are two other theoretical reasons why a negative relationship could be expected, both of which are related to multitasking behaviour. Firstly, the desire to use one's smartphone in order not to miss anything that is happening online-nowadays often referred to as 'FOMO' (fear of missing out)-and to continuously interact with the rest of the world may lead to a lack of the kind of focus necessary to achieve good study performance (Chen and Yan, 2016; Firat, 2013). Secondly, 
the constant switching back and forth between study-related and social activities on the smartphone could result in cognitive overload and inefficiency (Chen and Yan, 2016; Compernolle, 2014; Oulasvirta et al., 2012).

The recent empirical literature on this phenomenon is in line with the dominance of mechanisms that predict a negative relationship between smartphone use and educational performance. We are aware of seven studies that directly investigated their empirical association: Chen and Ji (2015), Lepp et al. (2014), Lepp et al. (2015), Li et al. (2015), Ng et al. (2017), Olufadi (2015), and Wentworth and Middleton (2014). More specifically, analysing survey data from the United States, Lepp et al. $(2014,2015)$ and Li et al. (2015) found a negative association between total smartphone use and the actual or self-reported grade point average (GPA) of college students, while Wentworth and Middleton (2014) concluded that there was no such association in their data. In addition, Ng et al. (2017) and Olufadi (2015) determined a negative association between mobile phone use during tertiary education and GPA in Malaysia and Nigeria, respectively. Finally, Chen and Ji (2015) reported that university students in Taiwan who used their personal electronic device(s) more for non-educational pursuits, had a lower first-year GPA. We refer to Amez et al. (2018) for a thorough review of this literature. ${ }^{1}$

As several of these studies themselves indicated, however, no causal interpretation can be given to any of their results. This is due to an endogeneity problem. The studies' results were obtained through correlation analyses and/or (multiple) linear or logistic regression analyses based on cross-sectional data. As a consequence, the measured non-positive association between smartphone use and academic performance might reflect variation in unobserved personal characteristics, such as intelligence, general ability, and motivation, which these studies did not control for, but which could affect both smartphone use and

\footnotetext{
1 In addition, a few other articles relate smartphone addiction (instead of general use) to educational underperformance (Hawi and Samaha, 2016; Samaha and Hawi, 2016). Besides this literature on the association between general smartphone use (and addiction) and educational performance, a further few articles exist that examine the association between the use of specific electronic applications (via one's smartphone and/or other devices) and study performance. For example, previous research investigated the association between study performance and the extent to which people call (Jacobsen and Forste, 2011) and check Facebook (Lee, 2014). However, these studies ignore the fact that the use of electronic devices for a particular application is strongly correlated with their use for other activities (Chen and Yan, 2016; Lepp et al., 2015), potentially resulting in an omitted variable bias. Finally, work has been done on the effectiveness of smartphone ban interventions in classrooms (Beland and Murphy, 2015).
} 
academic performance. This is an important limitation. As long as there is uncertainty as to whether the negative association between smartphone use and educational performance reflects a causal relationship (and not merely a correlation via confounding factors), there is no solid basis for interventions such as the smartphone ban in French schools (Samuel, 2017).

This study is the first to attempt to measure the causal impact of (overall) smartphone use on educational performance. To this end, we exploit data from 696 first-year students at two Belgian universities, who were surveyed in December 2016 using multiple scales on smartphone use as well as predictors of this smartphone use and a battery of questions concerning (potential) other drivers of success at university. This information is merged with the students' scores on their first exams, taken in January 2017. We analyse the merged data by means of instrumental variable estimation techniques. More concretely, to be able to correctly identify the influence of smartphone use on academic achievement, in a first stage, the respondents' smartphone use is predicted by diverging sets of variables that are highly significantly associated with smartphone use, but not directly associated with educational performance. In a second stage, the exam scores are regressed on this exogenous prediction of smartphone use and the largest set of control variables used in the literature to date.

The remainder of this article is structured as follows. In Section 2, we inform the reader about the data gathered to meet our research goals and about our approach to the making of causal inferences based on these data. Then, in Section 3, we discuss the findings of our main analyses and provide some robustness checks. The final section states our conclusions, with a preview for potential further research.

\section{Methods}

\subsection{Research Population}

The data used to investigate the effect of smartphone use on academic performance comes from merging unique survey data from first-year university students in Belgium with their 
first university exam scores. Our survey took place at the end of their first semester, in December 2016, i.e. just before the start of the Christmas holidays. Students use these holidays to prepare for their first semester exams, which take place immediately after the Christmas holidays. More concretely, we surveyed all students attending the last lecture of a first-semester course in all 11 Bachelor programs in three faculties at Ghent University and University of Antwerp, i.e. the two main universities in the two largest cities in Flanders, namely Ghent and Antwerp. These programs are: Business and Economics, Commercial Sciences, and Public Administration and Management in the faculty of Economics and Business Administration at Ghent University; Business Economics, Economic Policy, Business Engineering, and Management Information Systems in the faculty of Applied Economics at University of Antwerp; and Communication Studies, Political Science, Social and Economic Sciences, and Sociology in the faculty of Social Sciences at University of Antwerp.

In total, 1,117 students attended the classes at the start of which we gathered our survey data. This was done by means of a paper-and-pencil questionnaire. Among these students, 767 indicated, as a part of the survey, that they were in their first year at university (the other ones had had to resit the course, or were taking it as an elective course in the context of another program). We retained only this homogeneous group of first-year students. ${ }^{2}$ At the end of the survey, the attending students were asked whether they consented to their answers being merged with their first-semester exam scores by a third party, and 747 of the 767 first-year students consented. For 17 of them, no exam scores were observed, as they had dropped their courses by the end of the exam period. Finally, we had to exclude 18 students who indicated that they did not have smartphones, and 16 students with missing or inconsistent information. Consequently, our analyses are based on a sample of 696 firstyear students with complete information.

\footnotetext{
${ }^{2}$ An important advantage of excluding other students is that all first-year students in the same program took exactly the same courses, so that comparing their average exam result is more adequate than comparing the average results of students with a different set of exams. As we only observe the exam scores for the first-year courses, we are not able to control for the program composition of non-freshmen. Nevertheless, in Section 3.2, we report a robustness check in which non-freshmen are included in the sample.
} 


\subsection{Data}

We surveyed smartphone use by means of three indicators. Firstly, we let the participants fill in the Smartphone Usage Subscale of Rosen et al. (2013). This scale comprises nine items in which respondents indicate the frequency with which they use their smartphone for nine activities (such as 'making and receiving mobile phone calls' and 'checking for text messages'), rated on a 10-point frequency scale (ranging from 'never' to 'all the time'). These items were averaged to derive a scale from 1 to 10 , with higher scores indicating more frequent smartphone use. The Cronbach's alpha on this scale for our sample was 0.746 . In the remainder of the present manuscript, we refer to this scale as 'overall smartphone use'. In addition, by analogy with Rosen et al. (2016), we surveyed the participants on their smartphone use during classes and during study activities by means of the following items: 'During a typical class period, how often do you check your smartphone for something other than the time?' and 'During a typical hour of studying, how often do you check your smartphone for something other than the time?'. These had to be scored on a 7-point frequency scale (ranging from 'never' to 'more than eight times'; Rosen et al., 2016). In the remainder of this manuscript, we refer to these scores as 'smartphone use while attending class' and 'smartphone use while studying'. Panel A of Table 1 presents the average scores for the three indicators of smartphone use in our sample. The average score with respect to overall smartphone use is 5.701, while the average score with respect to smartphone use while attending class and while studying is 4.499 (i.e. between three and five times per course period) and 3.198 (i.e. close to two times per hour of study), respectively.

\section{$<$ Table 1 about here>}

Next, we gathered information on variables that were important for our statistical analysis being predictors of smartphone use that were assumed to have no independent impact on exam scores. These potential instruments - the adequacy of diverging sets of which are tested in Section 3-are: (i) whether the respondent had $4 \mathrm{G}$ technology on their smartphone (binary variable); (ii) six binary variables capturing the respondents' smartphone contracts (i.e. whether the monthly download volume included in the contract was $1 \mathrm{~GB}$ or more, as well as indicators of having Proximus, Base, Orange, Telenet, or another player as an operator); (iii) perceived quality of the Wi-Fi network in the respondents' classrooms (based on the respondents' answers to the item 'How do you evaluate the 
average quality of your Internet access in the classrooms this semester?', ranging from 1 (very bad) to 5 (very good)); and (iv) whether the respondents had to pay their smartphone costs themselves (binary variable). Panel B of Table 1 shows the respondents' average scores on these instruments, for the full sample as well as for the subsamples of individuals with a below-average versus above-average score on the overall smartphone use scale. The indicators of $4 \mathrm{G}$ technology and a substantial download volume show the highest correlations with smartphone use.

With respect to (additional) control variables for our analyses, firstly, we constructed indicator variables of the programs in which the data were gathered. In addition, we surveyed the respondents on the socioeconomic determinants of exam scores proposed in Baert et al. (2015): gender, age, (foreign) origin, language spoken at parental home, paternal education-we also surveyed maternal education, but this turned out to be heavily correlated with paternal education, so that we did not retain this construct for our analyses-household composition, relationship status, general health, living in a student room (versus at home), distance between home and university, and prior educational attainment. In addition, we let the respondents fill in the 28 items of the College Version of the Academic Motivation Scale of Vallerand et al. (1992), yielding a motivation score between 1 and 7, and the six items of the Webexec scale of Buchanan et al. (2010), yielding a measure of executive functioning problems between 1 and 5. A final control variable captured by our survey was whether or not the respondents used their laptop (versus paper and pencil) to take notes during classes most of the time. As shown in Panel C of Table 1, the subsample of individuals with a relatively high smartphone use particularly comprises more students (i) in the Political Science program, (ii) with a migration background, (iii) in (fairly) bad health, (iv) using their laptop to take notes in class, (v) living close to university, and (vi) having graduated from secondary education with low marks. As these factors are also likely to affect academic performance, controlling for them is desirable when identifying the impact of smartphone use on exam scores.

Finally, Panel D of Table 1 presents statistics on the three academic outcome variables we constructed based on the respondents' exam scores for their first semester at university. Our main outcome variable ('average score: completed exams') is the average of the respondents' scores (graded between 0 and 20) over all exams sat by them, leaving out 
observations for which they were not present at the exam. A first alternative outcome variable ('average score: potential exams') equals our main outcome variable except that the exam score for when students did not show up is recoded as the minimum score of 0 . A second alternative outcome variable ('fraction of exams passed') is calculated by dividing the number of exams the respondents passed (by obtaining at least 10 out of 20 points) by their total number of exams taken. ${ }^{3}$ In line with the correlational literature cited in Section 1 , all academic performance indicators are substantially less beneficial in the subsample of respondents with relatively high smartphone use. However, this comparison does not take into account selection, neither on the observable respondent characteristics listed in Panel C of Table 1, nor on the unobservable characteristics that may correlate with both smartphone use and academic performance. The instrumental variable regression approach we discuss in the following subsection deals with this double endogeneity problem.

\subsection{Empirical Approach}

Our main strategy for tackling the endogeneity of smartphone use (as captured by one of the variables in Panel A of Table 1) and academic performance (as captured by one of the variables in Panel $D$ of Table 1 ) is to rely on an instrumental variable regression framework (Angrist and Pischke, 2008; Baert et al., 2015). In the first stage of this two-stage least squares (2SLS) approach, the respondents' smartphone use is predicted by (a selection of) the instrumental variables included in Panel B of Table 1. As these variables are assumed to affect educational performance (after controlling for the other drivers of success at university included in Panel $\mathrm{C}$ of Table 1) only indirectly through actual smartphone use, this first stage yields an 'exogenous prediction' of the respondents' smartphone use. In the second stage, academic performance is regressed on this predicted smartphone use (and the control variables).

Our instrumental variables all are expected to be relevant as they put limits on one's access to the Internet and, therefore, to one's smartphone use during the day (as many smartphone applications, such as communication applications and news applications, require Internet access). This is obviously the case for access to $4 \mathrm{G}$ technology, monthly

\footnotetext{
${ }^{3}$ Analyses at the individual exam score level (with course fixed effects) yielded very similar research conclusions.
} 
download volume and perceived quality of the Wi-Fi network in the respondents' classrooms. In addition, as the Internet access (as well as the telephone connection) differs by (place and by) operator in Flanders, the student's operator may also correlate with her/his smartphone use. The same is true with respect to whether the respondents have to pay their smartphone costs themselves as this might affect smartphone contract type and, as a consequence, download volume and operator.

With respect to the exogeneity of our instruments, one might wonder why some of them (the one capturing whether the respondent pays her/his smartphone costs herself/himself in particular) are not directly associated with exam outcomes via household wealth. With respect to this concern, it is important that in our analyses we control for factors related to household wealth such as paternal education level and an indicator for broken households. Moreover, this concern should be looked at from the perspective of today's availability of and accessibility to smartphones irrespective of one's background characteristics (at least in the OECD countries). Indeed, literature on the relationship between socio-economic background and smartphone use seems to suggest that while there are differences in how smartphones are used across individuals from different backgrounds, this background is unrelated to smartphone accessibility (Frias-Martinez and Virsesa, 2012; Rahmati et al., 2012). ${ }^{4}$

In addition, both assumptions on which the causal interpretation of our results is based (relevance and exogeneity) are tested empirically. Firstly, with respect to the strength of our instrumental variables (i.e. their predictive power concerning smartphone use), we conduct F-tests of their joint significance in the first stage of the 2SLS regressions. Secondly, with respect to exogeneity of our instrumental variables, we present overidentification tests (Basmann, 1960; Sargan 1958). Besides these empirical tests, we conduct (i) a robustness check with a limited information maximum likelihood (LIML) approach instead of our benchmark 2SLS approach to overcome a potential weak instrument problem (Wooldridge, 2010) and (ii) a robustness check in which alternative combinations of instrumental variables are used to prove that our identification does not hinge on a particular instrument

\footnotetext{
${ }^{4}$ From Panel $\mathrm{C}$ of Table 1, it can be seen that smartphone use hardly varies by paternal education level. The same is true with respect to our instrumental variables, i.e. they do not seem to be substantially correlated with the household's socioeconomic status.
} 
combination.

Besides being the first study in the literature on (general) smartphone use and educational performance to apply a statistical technique that controls for unobserved determinants of academic success, in our analyses we also control for a set of individual performance determinants that is larger than those used in the previous research mentioned in Section 1. Consequently, we minimise the number of factors influencing both smartphone use and academic performance that are omitted from the regression analysis and estimate the effect of smartphone use within homogeneous subgroups of individuals. Thereby, the ordinary least squares (OLS) estimates to which we compare our 2SLS estimates should already approximate the true effect of smartphone use on educational performance (for our sample) more closely than the corresponding estimates reported in previous studies.

\section{Results}

\subsection{Main Analysis}

Table 2 presents the main estimation results of our benchmark analysis. This analysis comprises six regressions in which our main outcome variable, i.e. the respondent's average score on her/his completed exams, is explained by diverging independent variables (i.e. the overall smartphone use scale in models (1) and (2), smartphone use while attending class in models (3) and (4), and smartphone use while studying in models (5) and (6)) and all control variables mentioned in Panel C of Table 1. In columns (1), (3), and (5), we present OLS estimates, while in columns (2), (4), and (6), we present-our preferred-2SLS estimates exploiting the variation in all instruments listed in Panel B of Table 1. The full estimation results of model (2) are shown in Table A1 in online Appendix.

\section{$<$ Table 2 about here $>$}

Irrespective of the estimation method used and the indicator of smartphone use chosen, we find negative coefficients of this indicator, which are significantly different from 0 at least at the 5\% significance level. According to our 2SLS estimates in column (2) of Table 2, a unit 
increase on the overall smartphone use scale yields a decrease in exam score by 0.981 points ( $p=0.004)$, ceteris paribus. In other words, given that the standard deviation (SD) of the overall smartphone use scale is 0.925 , an increase on the overall smartphone use scale with one SD decreases the average exam score by 1.061 (i.e. $0.981 / 0.925$ ) points. As a consequence, the effect of an increase of smartphone use with one SD is similar to the effect of Dutch not being the main language at home (decrease in exam score by 0.992 points, compared with Dutch as main language) and somewhat higher than the effect of having divorced parents (decrease by 0.706 points) and the effect of a one SD decrease in motivation (decrease by 0.829 points, i.e. -1 [decrease] $\times 0.498$ [coefficient] / 0.601 [SD of academic motivation scale]).

It is well established in the literature that even small increases in pupil achievement can have important impacts in the long term, for instance with respect to their future earnings, but also with respect to economic growth (Jamison et al., 2007; Marconi, 2018; Mulligan, 1999; Murnane et al., 2000). In particular, based on data from the United States, Murnane et al. (2000) estimated, that an increase in high school seniors' math test scores by one quarter of a SD results in an annual earnings increase of $3.7 \%$ at the age of 30 . If, therefore, we assume that also a reduction in average exam score by 1.061 (which is slightly higher than one fourth of the SD of the average exam result, i.e. 3.203) due to a higher smartphone use results in a gross annual earnings decrease of $3.7 \%$ at the age of 30 , and if this earnings decrease were constant for each of the following 35 years until retirement age of 65 , then, following our back-of-the-envelope calculation, the present discounted value of the gross earnings decrease would be approximately $€ 25,000$, which is not a negligible amount. ${ }^{5}$

In addition, a one-standard-deviation increase on the scales with respect to smartphone use while attending class $(S D=1.724)$ and studying $(S D=1.586)$ yields a decrease in the average exam score with 0.512 (i.e. $0.883 / 1.724$ ) and 0.449 (i.e. $0.712 / 1.586$ ) points, respectively.

\footnotetext{
5 The "back-of-the-envelope" estimate of a $€ 25,000$ present discounted value is calculated as follows. The average yearly annual gross earnings at age 30-34 in Belgium, for both men and women, is approximately $€ 36,000$ (source: Statbel, the Belgian statistical office). A decrease of 3.7 percent amounts to $€ 1,332$. Assuming this decrease in gross annual earnings is constant over 35 years and assuming a real discount rate of 0.040 , the present discounted value is about $€ 25,000$.
} 
Interestingly, the magnitude of these $2 \mathrm{SLS}$ estimates is more than twice that of the corresponding OLS estimates. This suggests that university students with a relatively high smartphone use are a negatively selected subpopulation-negatively selected with respect to unobserved success determinants of academic performance-of the overall population of university students. ${ }^{6}$ The need to control for unobserved heterogeneity in this context is also revealed by the p-values of the Hausman endogeneity tests we performed based on models (2), (4), and (6). Exogeneity of the adopted smartphone use indicators is, even after controlling for a large set of controls, rejected at the 5\% significance level for model (4), rejected at the $10 \%$ significance level for model (6), and close to rejection at the $10 \%$ significance level for model (2). Moreover, Table 2 provides empirical support for the two crucial assumptions underlying our 2SLS approach mentioned in Section 2.3. Firstly, the used instruments are significant predictors of our smartphone use indicators - the p-value of the related F-test is always 0.000 . Secondly, the Basmann overidentification test is never (close to) significant, supporting the exogeneity of the used instruments with respect to exam scores.

We briefly discuss some secondary results concerning the other determinants of academic success adopted in our models as controls. Table A1 shows that exam scores are higher among those students (i) starting university at a younger age (ergo, with less or no grade retention during their secondary education), (ii) having Dutch as the main language spoken at home, (iii) not having divorced parents, (iv) showing a higher academic motivation, (v) living in a student room, (vi) living closer to the university, and (vii) having graduated from secondary education with high marks. A structural interpretation of the coefficients for these control variables is hazardous, however, as they might be endogenous to educational performance.

\subsection{Robustness Checks}

In what follows, we report on the results of several analyses performed to check the robustness of our benchmark analysis. Firstly, we test the robustness of our results for the use of alternative outcome variables, i.e. the respondents' average scores on their potential

\footnotetext{
${ }^{6}$ We provide an alternative explanation when we discuss our research limitations in Section 4.
} 
exams (instead of completed exams) and the fraction of completed exams they pass. The OLS and 2SLS estimates with respect to the former alternative outcome variable are presented in columns (3) and (4) of Table 3, respectively, while the corresponding estimates with respect to the latter alternative outcome variable are presented in columns (5) and (6). To facilitate comparison between these estimation results and those in our benchmark analysis, we adopt columns (1) and (2) of Table 2 as columns (1) and (2) of Table 3. The results in column (4) are very close to those in column (2): a unit increase on the overall smartphone use scale decreases the exam score averaged over all potential exams with 0.848 points $(p=0.014)$. In addition, a unit increase on the overall smartphone use scale yields a decrease in the respondents' fraction of passed exams by 7.6 percentage points ( $p$ $=0.044)$, ceteris paribus. Therefore, higher smartphone use does not only negatively affect exam scores but these lower exam scores also result in a higher probability of failing courses.

\section{$<$ Table 3 about here $>$}

Secondly, we test the robustness of our results for the use of alternative sets of instrumental variables to identify our 2SLS estimates of the effect of smartphone use on exam scores. More concretely, in Table A2 in online Appendix, we present the main estimation results of six 2SLS models, in which, starting from the specification of model (2) in our benchmark analysis, two out of four (clusters of) instruments are dropped. Stated otherwise, identification of regressions (2) to (7) of Table A2 is based on two out of the four (clusters of) instruments used in model (2) of Table 2 only. ${ }^{7}$ However, our findings turn out to be fairly independent of which set of instruments we used. ${ }^{8}$

Thirdly, we approach the endogeneity problem in an alternative way, starting from our OLS model instead of relying on our 2SLS estimates. More concretely, we run tests for selection on unobservables for the OLS results by analogy with Oster (2017) and Galletta (2017). The results are presented in Table 4. The crucial parameter in this table is $\delta$, which indicates how large the selection on unobservables (relative to the selection on the included

\footnotetext{
${ }^{7}$ Also regressions where only one (cluster of) instrument(s) is used, yield the same conclusion of a negative effect, albeit somewhat less precisely estimated.

8 The somewhat lower significance of the effect of smartphone use in Column (6) and Column (7) of Table A2 may be related to a weak instrument problem (as supported by the p-value of the F-test, which is in these cases slightly higher than 0.000; Angrist and Pischke, 2008). We return to this point below.
} 
variables) has to be for the independent variable to become 0 . As can be seen, the computed $\delta$ with respect to the overall smartphone use is 5.622 such that the effect of the unobservables needs to be 5.622 times stronger than that of observables to completely nullify the effect of overall smartphone use, which is not likely. In general, a value for $\delta$ higher than 1 is the threshold usually considered labelling results as robust (Galletta, 2017; Oster, 2017). This is the case for all regressions of our benchmark analysis.

\section{$<$ Table 4 about here $>$}

Fourthly, to cope with a potential bad control problem, we replicate Table 2 after dropping the insignificant controls, regression by regression. The main estimation results can be found in Table A3 in online Appendix. However, these results are very similar to those in Table 2. Fifthly, although there is no indication of a weak instrument problem in our benchmark analysis, we estimate LIML regressions, of which the main results are presented in Table A4. Also these estimates are similar to those in Table 2 although the magnitude of the estimated treatment effects is somewhat higher. Finally, Table A5 presents the results of replicating Table 2 after extending the sample with the surveyed individuals not being in their first year at the university. This yields treatment effects that are somewhat higher in magnitude. Moreover, after including these individuals, exogeneity of the smartphone use indicators is rejected at a higher significance level, supporting our 2SLS approach even more.

\subsection{Heterogeneous Treatment Effects}

To explore the mechanisms at play, we extend model (1) of our benchmark analysis with interactions between overall smartphone use and the control variables (except for the program indicators). Firstly, in models (1) to (5) of Table 5, we introduce these interactions cluster-by-cluster: interactions with sociodemographic characteristics in (1), with health, motivation and functioning problems in (2), with laptop use in (3), with place of living in (4), and with secondary school outcomes in (5). Secondly, in model (6), all interactions are included jointly. Three interactions are statistically significant at the $5 \%$ significance level. ${ }^{9}$

\footnotetext{
${ }_{9}^{9}$ With respect to the insignificant coefficients, it is particularly interesting that (general) smartphone use and laptop use (in class) do not seem to work as complements (no significantly positive interaction) or supplements (no significantly negative interaction).
} 
That is, the negative association between smartphone use and exam results is more outspoken for students (i) with highly educated fathers, (ii) with divorced parents and (iii) who are in good health. ${ }^{10}$

\section{$<$ Table 5 about here $>$}

While, in our opinion, the first significant interaction, i.e. with paternal education level, is not an argument in favour or against any of the theoretical mechanisms discussed in Section 1-students from richer families may just use their smartphone in another waythe second and third interaction are in line with the mechanisms related to multitasking behaviour. More concretely, students raised by divorced parents might experience a higher need to strong social relationships. This need can raise the FOMO and, therefore, increase smartphone multitasking (Chen and Yan, 2016). This stronger tendency to multitasking behaviour might lie behind the higher association between smartphone use and academic performance for these students. In addition, students with a poorer health might focus completely (or at least more) on their primary task, that is studying, because they are aware of their lower energy. Due to this awareness, those students may engage less in multitasking behaviour. As such, students with poorer health will experience a smaller negative association between smartphone use and academic performance.

To further explore the driving factors underlying the negative association between smartphone use and exam results, we run OLS regressions with alternative independent variable combinations. ${ }^{11}$ The main estimation results can be found in Table $A 6$ in online Appendix. Firstly, we present the main estimation results after including the three smartphone use variables of our benchmark analysis jointly. In model (1) we include all controls, in model (2) only the significant controls of model (1) are adopted. We find that high overall smartphone use and high smartphone use while attending class are independently associated with bad exam results (at the $1 \%$ significance level). However, the

\footnotetext{
10 While the interaction with 'fairly good' health is significant, the interaction with 'very good' health is insignificant. However, the parameter estimates for both interactions are quite similar and an F-test indicates that their equality cannot be rejected $(p=0.297)$.

11 When we run 2SLS regressions with all three endogenous smartphone use variables jointly, the sign of the estimated effects is as expected, however, presumably due to the relatively small sample size, none of the estimated effects are significant.
} 
association between smartphone use while studying and exam results becomes virtually 0 after including the two other indicators. ${ }^{12}$ This suggests that sensitising students to moderate their smartphone use while attending class makes sense. In addition, the fact that overall smartphone use remains significant after controlling for smartphone use while attending class and while studying, can be seen as suggestive evidence for the trade-off in time use mechanism.

Secondly, instead of using the overall smartphone use scale as the single independent variable, as in our benchmark analysis, in model (3) and model (4) of Table A6, we adopt all nine items comprised by this scale separately. The main estimation results indicate that taking pictures is the activity with the strongest independent association with exam results. Again, this is in line with the trade-off in time use mechanism, i.e. students who use their smartphone for fun experience a more negative association between this use and exam results.

\section{Conclusions}

In this study, we contributed to recent literature concerning the association between smartphone use and educational performance by providing estimates of the effect of the former on the latter based on instrumental variable estimation techniques. To this end, we analysed unique data on 696 first-year university students in Belgium. We found that a onestandard-deviation increase in their overall smartphone use yields a decrease in their average exam score of about one point (out of 20). This negative relationship is robust to the use of alternative indicators of smartphone use and academic performance. The negative association between smartphone use and exam results is more outspoken for students (i) with highly educated fathers, (ii) with divorced parents and (iii) who are in good health.

\footnotetext{
12 This is not very surprising given the substantial Pearson's correlation coefficient between smartphone use while studying and (i) overall smartphone use $(\rho=0.208)$ and (ii) smartphone use while attending class $(\rho=$ 0.500).
} 
As our results add to the literature evidence for heavy smartphone use not only being associated with lower exam marks but also causing lower marks, we believe that policymakers should at least invest in information and awareness campaigns of teachers and parents to highlight this trade-off. In particular, smartphone use in class might be discouraged since secondary analyses showed that it is highly significantly associated with lower exam results even after controlling for overall smartphone use and smartphone use while studying. Recent announcement of mobile phone ban for French school students, followed by the debates on the issue in Denmark, Sweden and the United Kingdom, suggest that the use of mobile phones in schools and universities needs to have a proper conversation among the policy makers. ${ }^{13}$

We end this article by acknowledging its main limitations, which also point to future research possibilities. Firstly, we measured the impact of smartphone use on exam scores for first-year university students attending classes in 11 study programs at three faculties in Belgium. Although we have no a priori reasons to expect that the relationship between smartphone use and academic performance would be different for other groups of students and/or other regions, our results cannot be automatically generalised to these other groups. Therefore, we are in favour of studies complementing our findings via similar investigations based on data from other kind of students and other regions.

Secondly, as discussed extensively, the causal interpretation of our regression results is conditional on the validity of the instrumental variables used in our statistical framework. In this respect, it should be acknowledged that our instruments do not capture real exogenous shocks affecting smartphone use but rather cross-sectional variation that is assumed (and tested) not to directly affect (or be directly affected by) academic performance. In addition, some of these instruments might rather predict smartphone use length instead of smartphone use frequency, as captured by our independent variables. However, it is important to recall that our estimations were fairly independent of which set of two out of six potential instruments were used. In addition, we believe that by comparing ordinary least squares estimations - as relied on in the former contributions to this literature-with results

13 See: https://theconversation.com/banning-mobile-phones-in-schools-beneficial-or-risky-hereswhat-the-evidence-says-119456 
from instrumental variable regressions, we put a step forward in the investigation of the genuine relationship between smartphone use and academic performance. The fact that our more complex analyses confirm the (direction of) the correlational analyses of former contributions is, in our opinion, a valuable input, for both scholars and policy makers. Future research could rely on (quasi) experimental evidence, less prone to the issues mentioned above.

Thirdly, even when instrumental variables are valid-and empirical tests supported that this was the case in our analyses-2SLS estimations always only isolate a local average treatment effect (LATE; Angrist and Pischke, 2008). That is, the effect of smartphone use measured in this study was identified based only on the respondents whose smartphone use was affected by the included instrumental variables. This is an alternative explanation for our 2SLS estimates being of a higher magnitude than the corresponding OLS estimates. In this respect, however, it is important to recall that the higher smartphone use effects found based on our preferred approach were independent of which particular set of instruments was adopted. Nevertheless, we look forward to future work measuring the causal impact of smartphone use on academic performance using other statistical approaches (e.g. fixed-effects estimations exploiting longitudinal data).

\section{References}

Abouk, Rahi and Scott Adams (2013). Texting bans and fatal accidents on roadways: Do they work? Or do drivers just react to announcements of bans? American Economic Journal: Applied Economics, 5(2): 179-199.

Amez, Simon, De Marez, Lieven, and Stijn Baert (2018). Smartphone use and academic performance: A literature review. Mimeo.

Andreassen, Cecilie S. (2015). Online social network site addiction: A comprehensive review. Current Addiction Reports, 2(2): 175-184.

Angrist, Joshua and Jörn-Steffen Pischke (2008). Mostly armless Econometrics: An Empiricist's Companion. Princeton: Princeton University Press. 
Baert, Stijn, Verhaest, Dieter, Vermeir, Aurélie, and Eddy Omey (2015). Mister Sandman, bring me good marks! On the relationship between sleep quality and academic achievement. Social Science \& Medicine, 130: 91-98.

Barkley, Jacob E. and Andrew Lepp (2013). Cellular telephone use is associated with greater sedentary behavior independent of leisure time physical activity. Applied Physiology, Nutrition, and Metabolism, 38(10): 1023.

Basmann, Robert L. (1960). On finite sample distributions of generalized classical linear identifiability test statistics. Journal of the American Statistical Association, 55(292): 650-659.

Becker, Gary S. (1965). A theory of the allocation of time. Economic Journal, 75(299): 493517.

Beland, Louis-Philippe and Richard Murphy (2016). III Communication: Technology, distraction \& student performance. Labour Economics, 41(SI), 61-76.

Bhargava, Saurabh and Vikram S. Pathania (2013). Driving under the (cellular) influence. American Economic Journal: Economic Policy, 5(3): 92-125.

Buchanan, Tom, Heffernan, Thomas M., Parrott, Andrew C., Ling, Jonathan, Rodgers, Jacqui, and Andrew B. Scholey (2010). A short self-report measure of problems with executive function suitable for administration via the Internet. Behavior Research Methods, 42(3): 709-714.

Chen, Quan and Zheng Yan (2016). Does multitasking with mobile phones affect learning? A review. Computers in Human Behaviour, 54: 34-42.

Chen, Ru-Shen and Chang-Ho Ji (2015). Investigating the relationship between thinking style and personal electronic device use and its implications for academic performance. Computers in Human Behavior, 52: 177-183.

Compernolle, Theo (2014). Ontketen je brein. Hoe hyperconnectiviteit en multitasking je hersenen gijzelen en hoe je eraan kunt ontsnappen. Tielt: Lannoo.

Eliahu, Jim (2014). 10 ways smartphones have completely ruined our lives. Retrieved on 21 November 2017 from https://thoughtcatalog.com/jim-eliahu/2014/04/10-wayssmartphones-have-completely-ruined-our-lives/. 
Firat, Mehmet (2013). Multitasking or continuous partial attention: A critical bottleneck for digital natives. Turkish Online Journal of Distance Education, 14(1): 1302-6488.

Frias-Martinez, Vanessa and Jesus Virsesa (2012). On the relationship between socioeconomic factors and cell phone usage. Mimeo.

Galletta, Sergio (2017). Law enforcement, municipal budgets and spillover effects: Evidence from a quasi-experiment in Italy. Journal of Urban Economics, 101: 90-105.

Hanushek, Eric A. and Dennis D. Kimko (2000). Schooling, labor-force quality, and the growth of nations. American Economic Review, 90(5): 1184-1208

Hawi, Nazir S. and Maya Samaha (2016). To excel or not to excel: Strong evidence on the adverse effect of smartphone addiction on academic performance. Computers \& Education, 98: 81-89.

Jacobsen, Wade C. and Renata Forste (2011). The wired generation: Academic and social outcomes of electronic media use among university students. Cyberpsychology, Behavior, and Social Networking, 14(5): 275-280.

Jamison, Eliot A., Jamison, Dean T., and Eric A. Hanushek (2007). The effects of education quality on income growth and mortality decline. Economics of Education Review, 26(6): $772-789$.

Lee, Bun E. (2014). Facebook use and texting among African American and Hispanic teenagers: An implication for academic performance. Journal of Black Studies, 45(2): 83101.

Lepp, Andrew, Barkley, Jacob E., and Aryn C. Karpinski (2014). The relationship between cell phone use, academic performance, anxiety, and satisfaction with life in college students. Computers in Human Behavior, 31: 343-350.

Lepp, Andrew, Barkley, Jacob E., and Aryn C. Karpinski (2015). The relationship between cell phone use and academic performance in a sample of U.S. college students. SAGE Open, 5(1): 1-9.

Lepp, Andrew, Barkley, Jacob E., Sanders, Gabriel J., Rebold, Michael, and Peter Gates (2013). The relationship between cell phone use, physical and sedentary activity, and cardiorespiratory fitness in a sample of U.S. college students. International Journal of 
Behavioral Nutrition and Physical Activity, 10: 79.

Levine, Laura E., Waite, Bradley M., and Laura L. Bowman (2012). Mobile media use, multitasking and distractibility. International Journal of Cyber Behavior, Psychology and Learning, 2(3): 15-29.

Li, Jian, Lepp, Andrew, and Jacob E. Barkley (2015). Locus of control and cell phone use: Implications for sleep quality, academic performance and subjective well-being. Computers in Human Behavior, 52: 450-457.

Marconi, Gabriele (2018). Education as a long-term investment: The decisive role of age in the education-growth relationship. Kyklos, 71(1): 132-161.

Mulligan, Casey B. (1999). Galton versus the human capital approach to inheritance. Journal of Political Economy, 107(S6): S184-S224.

Murnane, Richard J., Willett, John B., Duhaldeborde, Yves, and John H. Tyler (2000). How important are the cognitive skills of teenagers in predicting subsequent earnings? Journal of Policy Analysis and Management, 19(4): 547-568.

OECD (2017). OECD Digital Economy Outlook 2017. Paris: OECD.

Olufadi, Yunusa (2015). A configurational approach to the investigation of the multiple paths to success of students through mobile phone use behaviors. Computers \& Education, 86: 84-104.

Oster, Emily (2017). Unobservable selection and coefficient stability: Theory and evidence. Journal of Business \& Economic Statistics, doi: 10.1080/07350015.2016.1227711.

Oulasvirta, Antti, Rattenbury, Tye, Ma, Lingyi, and Eeva Raita (2012). Habits make smartphone use more pervasive. Personal and Ubiquitous Computing, 16(1): 105-114.

Ng, Siew Foen, Hassan, Nor Syamimi Illiani Che, Nor, Nor Hairunnisa Mohammad, and Nur Ain Abdul Malek (2017). The relationship between smartphone use and academic performance: A case of students in a Malaysian tertiary institution. Malaysian Online Journal of Educational Technology, 5(4): 58-70.

Rahmati, Ahmad, Tossell, Chad, Shepard, Clayton, Kortum, Philip, and Lin Zhong (2012). Exploring iPhone usage: The influence of socioeconomic differences on smartphone 
adoption, usage and usability. Mimeo.

Rosen, Larry, Whaling, Kelly, Carrier, L. Mark, Cheever, Nancy A., and Jeffrey N. Rokkum (2013). The Media and Technology Usage and Attitudes Scale: An empirical investigation. Computers in Human Behavior, 29(6): 2501-2511.

Rosen, Larry, Carrier, L. Mark, Miller, Aimee, Rokkum, Jeffrey, and Ana B.M. Ruiz (2016). Sleeping with technology: Cognitive, affective, and technology usage predictors of sleep problems among college students. Sleep Health, 2(1): 49-56.

Samaha, Maya and Nazir S. Hawi (2016). Relationships among smartphone addiction, stress, academic performance and satisfaction with life. Computers in Human Behavior, 57: $321-325$.

Samuel, Henry (2017). France to impose total ban on mobile phones in schools. Retrieved on 21 November 2017 from www.telegraph.co.uk/news/2017/12/11/france-imposetotal-ban-mobile-phones-schools/.

Sargan, John Dennis (1958). The estimation of economic relationships using instrumental variables. Econometrica 26(3): 393-415

Vallerand, Robert J., Pelletier, Luc G., Blais, Marc R., Briere, Nathalie M., Senecal, Caroline, and Evelyne F. Vallieres (1992). The Academic Motivation Scale: A measure of intrinsic, extrinsic and amotivation in education. Educational and Psychological Measurement, 52(4): 1003-1017.

Vanhaelewyn, Bart and Lieven De Marez (2017). Digimeter 2016: Measuring digital media trends in Flanders. Ghent: Imec.

Wentworth, Diane Keyser and June H. Middleton (2014). Technology use and academic performance. Computers \& Education, 78: 306-311.

Wooldridge, Jeffrey Marc (2010). Econometric Analysis of Cross Section and Panel Data. Cambridge: MIT Press. 


\begin{tabular}{|c|c|c|c|c|}
\hline & & (2) & (3) & (4) \\
\hline & \multicolumn{3}{|l|}{ Average } & \multirow[b]{2}{*}{ Difference: (3) - (2) } \\
\hline & $\begin{array}{l}\text { Full sample } \\
N=696\end{array}$ & $\begin{array}{l}\text { Subsample: Overall } \\
\text { smartphone use below } \\
\text { average } \\
\mathrm{N}=333\end{array}$ & $\begin{array}{l}\text { Subsample: Overall } \\
\text { smartphone use above } \\
\text { average } \\
\mathrm{N}=363\end{array}$ & \\
\hline \multicolumn{5}{|l|}{ A. Smartphone use } \\
\hline Overall smartphone use & 5.701 & 4.970 & 6.372 & $1.402 * * *[30.602]$ \\
\hline Smartphone use while attending class & 4.499 & 3.934 & 5.017 & $1.083^{* * *}[8.709]$ \\
\hline Smartphone use while studying & 3.198 & 2.958 & 3.419 & $0.461^{* * *}[3.866]$ \\
\hline \multicolumn{5}{|l|}{ B. Instrumental variables: predictors of smartphone use } \\
\hline 4G technology on smartphone & 0.846 & 0.769 & 0.917 & $0.149 * * *[5.540]$ \\
\hline Download volume of $1 \mathrm{~GB}$ or more & 0.451 & 0.390 & 0.507 & $0.116^{* * *}[3.102]$ \\
\hline Operator: Proximus & 0.352 & 0.378 & 0.328 & $-0.051[1.394]$ \\
\hline Operator: Base & 0.109 & 0.099 & 0.118 & 0.019 [0.817] \\
\hline Operator: Orange & 0.260 & 0.237 & 0.281 & $0.044[1.314]$ \\
\hline Operator: Telenet & 0.220 & 0.219 & 0.220 & $0.001[0.037]$ \\
\hline Operator: other & 0.059 & 0.066 & 0.052 & $-0.013[0.767]$ \\
\hline Perceived quality of Wi-Fi in classrooms & 3.555 & 3.491 & 3.614 & $0.123 *[1.915]$ \\
\hline Paying smartphone costs herself/himself & 0.168 & 0.159 & 0.176 & $0.017[0.604]$ \\
\hline \multicolumn{5}{|l|}{ C. Control variables } \\
\hline Program: University of Antwerp & 0.365 & 0.366 & 0.364 & $-0.003[0.075]$ \\
\hline Program: Ghent University, Business and Economics & 0.352 & 0.372 & 0.333 & $-0.039[1.077]$ \\
\hline Program: Ghent University, Commercial Sciences & 0.214 & 0.204 & 0.223 & $0.019[0.608]$ \\
\hline Program: Ghent University, Public Administration and Management & 0.069 & 0.057 & 0.080 & $0.023[1.187]$ \\
\hline Program: University of Antwerp, Business Economics & 0.151 & 0.141 & 0.160 & $0.019[0.686)$ \\
\hline Program: University of Antwerp, Economic Policy & 0.017 & 0.024 & 0.011 & $-0.013[1.316]$ \\
\hline Program: University of Antwerp, Business Engineering & 0.014 & 0.018 & 0.011 & $-0.007[0.774]$ \\
\hline Program: University of Antwerp, Management Information Systems & 0.053 & 0.057 & 0.050 & $-0.007[0.438]$ \\
\hline Program: University of Antwerp, Communication Studies & 0.042 & 0.045 & 0.039 & $-0.006[0.427]$ \\
\hline Program: University of Antwerp, Political Science & 0.016 & 0.006 & 0.025 & $0.019 * *[1.988]$ \\
\hline Program: University of Antwerp, Social and Economic Sciences & 0.043 & 0.036 & 0.050 & $0.014[0.879]$ \\
\hline Program: University of Antwerp, Sociology & 0.029 & 0.039 & 0.019 & $-0.020[1.559]$ \\
\hline Female & 0.510 & 0.508 & 0.512 & 0.005 [0.129] \\
\hline
\end{tabular}


Dutch is not main language at home

18.05

18.063

$0.012[0.367]$

Highest diploma father: no tertiary education

$\begin{array}{ll}0.152 & 0.123 \\ 0.099 & 0.081\end{array}$

Highest diploma father: tertiary education outside college

0.358

$0.299-0.294$

Highest diploma father: tertiary education in college

At least one parent passed away

Divorced parents

0.192

Number of siblings: none

$0.096-0.090$

Number of siblings: one

Number of siblings: two

Number of siblings: more than two

In a relationship

General health: (fairly) bad

General health: fairly good

General health: very good

Academic motivation scale

Executive functioning problems scale

$0.510 \quad 0.514$

0.297

$0.099-0.099$

0.387

$0.040 \quad 0.024$

$0.575 \quad 0.565$

$0.385-0.411$

$4.969+4.936$

1.801

Using laptop to take notes in class

0.171

Living in a student room

Distance between home and university (in $\mathrm{km}$ )

0.343

36.402

0.123

0.179

$0.056 * *[2.055]$

$0.035[1.527]$

$-0.011[0.295]$

$0.009[0.251]$

$0.002[0.056$

$0.007[0.614]$

$0.031[1.004]$

$0.012[0.528]$

$-0.007[0.174]$

$-0.005[0.153]$

$0.000[0.003]$

$-0.062 *[1.717]$

$0.031 * *[2.088]$

$0.019[0.518]$

$-0.051[1.368]$

$0.064[1.400]$

$0.056[1.587]$

$0.092 * * *[3.231]$

$-0.067 *[1.864]$

$-4.414 * *[2.316]$

Program in secondary education: Economics - maths

0.234

$0.094 * * *[2.749]$

Program in secondary education: Ancient languages

Program in secondary education: Exact sciences - maths

0.201

$-0.059 *[1.891$

Program in secondary education: other

0.153

$-0.025[0.839]$

$-0.013[0.471]$

$0.003[0.102]$

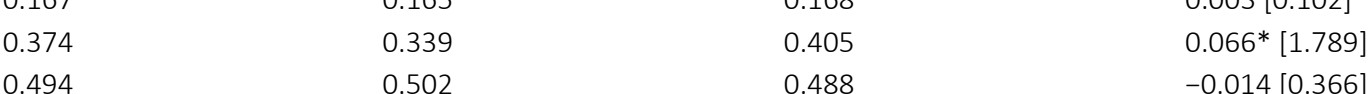

General end marks in secondary education: between $70 \%$ and $80 \% \quad 0.494$

General end marks in secondary education: more than $80 \%$

0.132

0.159

$-0.052 * *[2.016]$

$\begin{array}{llll}\text { D. Academic performance } & & 11.550 & 10.443 \\ \text { Average score: completed exams } & 10.973 & 11.442 & -1.107^{* * *}[4.620] \\ \text { Average score: potential exams } & 10.888 & -1.062^{* * *}[4.355] \\ \text { Fraction of exams passed } & 0.646 & 0.689 & -0.083^{* * *}[3.219]\end{array}$

Fraction of exams passed

$-0.083 * * *[3.219]$

Notes. See Section 2.2 for a description of the data. T-tests are performed to test whether the differences presented in Column $(3)$ are significantly different from $0 .{ }^{* * *}(* *)((*))$ indicates significance at the $1 \%(5 \%)((10 \%))$ significance level. T-statistics are between brackets. 
Table 2. Main Estimation Results: Benchmark Analysis

\begin{tabular}{|c|c|c|c|c|c|c|}
\hline & $(1)$ & (2) & (3) & (4) & (5) & (6) \\
\hline Estimation method & OLS & $2 S L S$ & OLS & $2 S L S$ & OLS & $2 S L S$ \\
\hline Outcome variable & $\begin{array}{l}\text { Average score: } \\
\text { completed exams }\end{array}$ & $\begin{array}{l}\text { Average score: } \\
\text { completed exams }\end{array}$ & $\begin{array}{l}\text { Average score: } \\
\text { completed exams }\end{array}$ & $\begin{array}{l}\text { Average score: } \\
\text { completed exams }\end{array}$ & $\begin{array}{l}\text { Average score: } \\
\text { completed exams }\end{array}$ & $\begin{array}{l}\text { Average score: } \\
\text { completed exams }\end{array}$ \\
\hline Instrumental variables & - & All & - & All & - & All \\
\hline Overall smartphone use & $-0.462^{* * *}(0.113)$ & $-0.981^{* * *}(0.338)$ & & & & \\
\hline Smartphone use while attending class & & & $-0.260^{* * *}(0.062)$ & $-0.883^{* * *}(0.288)$ & & \\
\hline Smartphone use while studying & & & & & $-0.134^{* *}(0.068)$ & $-0.712^{* *}(0.329)$ \\
\hline Additional control variables & All & All & All & All & All & All \\
\hline Hausman endogeneity test ( $p$-value) & - & 0.108 & - & 0.020 & - & 0.066 \\
\hline First stage: F-test of instruments' joint significance ( $p$-value) & - & 0.000 & - & 0.000 & - & 0.000 \\
\hline Sargan overidentification test ( $p$-value) & - & 0.564 & - & 0.853 & - & 0.309 \\
\hline Basmann overidentification test ( $p$-value) & - & 0.603 & - & 0.872 & - & 0.347 \\
\hline Number of observations & 696 & 696 & 696 & 696 & 696 & 696 \\
\hline
\end{tabular}

Note. OLS (2SLS) stands for ordinary least squares (two-stage least squares). See Section 2.2 for a description of the data. See Table A1 for the full regression results of model (2). The presented results are coefficient estimates, with standard errors in parentheses. ${ }^{* * *}\left({ }^{* *}\right)\left(\left(^{*}\right)\right)$ indicates significance at the $1 \%(5 \%)((10 \%))$ significance level. 
Table 3. Main Estimation Results: Alternative Outcome Variables

\begin{tabular}{|c|c|c|c|c|c|c|}
\hline & (1) & (2) & (3) & (4) & (5) & (6) \\
\hline Estimation method & OLS & $2 S L S$ & OLS & $2 S L S$ & OLS & $2 S L S$ \\
\hline Outcome variable & $\begin{array}{l}\text { Average score: } \\
\text { completed exams }\end{array}$ & $\begin{array}{l}\text { Average score: } \\
\text { completed exams }\end{array}$ & $\begin{array}{l}\text { Average score: } \\
\text { potential exams }\end{array}$ & $\begin{array}{l}\text { Average score: } \\
\text { potential exams }\end{array}$ & $\begin{array}{l}\text { Fraction of } \\
\text { exams passed }\end{array}$ & $\begin{array}{l}\text { Fraction of } \\
\text { exams passed }\end{array}$ \\
\hline Instrumental variables & - & All & - & All & - & All \\
\hline Overall smartphone use & $-0.462^{* * *}(0.113)$ & $-0.981^{* * *}(0.338)$ & $-0.432^{* * *}(0.116)$ & $-0.848^{* *}(0.345)$ & $-0.031^{* *}(0.013)$ & $-0.076^{* *}(0.038)$ \\
\hline Additional control variables & All & All & All & All & All & All \\
\hline Hausman endogeneity test ( $p$-value) & - & 0.108 & - & 0.209 & - & 0.210 \\
\hline First stage: F-test of instruments' joint significance ( $p$-value) & - & 0.000 & - & 0.000 & - & 0.000 \\
\hline Sargan overidentification test ( $p$-value) & - & 0.564 & - & 0.671 & - & 0.973 \\
\hline Basmann overidentification test ( $p$-value) & - & 0.603 & - & 0.705 & - & 0.977 \\
\hline Number of observations & 696 & 696 & 696 & 696 & 696 & 696 \\
\hline
\end{tabular}

Note. OLS (2SLS) stands for ordinary least squares (two-stage least squares). See Section 2.2 for a description of the data. The presented results are coefficient estimates, with standard errors in parentheses. ${ }^{* * *}\left({ }^{* *}\right)\left(\left({ }^{*}\right)\right)$ indicates significance at the $1 \%(5 \%)((10 \%))$ significance level. 
Table 4. Main Estimation Results: Selection on Unobservables

\begin{tabular}{|c|c|c|c|}
\hline & (1) & (3) & (5) \\
\hline Estimation method & OLS & OLS & OLS \\
\hline Outcome variable & $\begin{array}{l}\text { Average score: } \\
\text { completed } \\
\text { exams }\end{array}$ & $\begin{array}{l}\text { Average score: } \\
\text { completed } \\
\text { exams }\end{array}$ & $\begin{array}{l}\text { Average score: } \\
\text { completed } \\
\text { exams }\end{array}$ \\
\hline Overall smartphone use ( $\beta$ ) & -0.462 & & \\
\hline Smartphone use while attending class ( $\beta$ ) & & -0.260 & \\
\hline Smartphone use while studying ( $\beta$ ) & & & -0.134 \\
\hline Additional control variables & All & All & All \\
\hline$R^{2}$ & 0.361 & 0.361 & 0.348 \\
\hline Relative degree of selection on observed and unobserved variables $(\delta)$ & 5.622 & 3.802 & 1.980 \\
\hline Number of observations & 696 & 696 & 696 \\
\hline
\end{tabular}

Note. OLS stands for ordinary least squares. See Section 2.2 for a description of the data. The presented results are the coefficient estimates from the corresponding regressions in Table $2 . \delta$ is calculated by analogy with Oster (2017), using the Psacalc Stata module by Emily Oster. In particular, $R_{\max }$ (i.e. the hypothetical $R^{2}$ from a regression of the outcome variable on the smartphone use indicator and both the observed and unobserved controls) is set to be 1.3 times $\mathrm{R}^{2}$ from the regression of the outcome variable on the smartphone use indicator and the observed controls only (as presented in this table). $\delta$ tells how large the selection on unobservables has to be such that the coefficient of the smartphone use indicator ( 6 ) is 0 in the true model. A value for $\delta$ higher than 1 is the threshold usually considered to label results as robust (Galletta, 2017; Oster, 2017). 
Table 5. Main Estimation Results: Heterogeneous Effects

\begin{tabular}{|c|c|c|c|c|c|c|}
\hline & (1) & $(2)$ & (3) & (4) & (5) & (6) \\
\hline Estimation method & OLS & OLS & OLS & OLS & OLS & OLS \\
\hline Outcome variable & $\begin{array}{l}\text { Average score: } \\
\text { completed } \\
\text { exams }\end{array}$ & $\begin{array}{l}\text { Average score: } \\
\text { completed } \\
\text { exams }\end{array}$ & $\begin{array}{l}\text { Average score: } \\
\text { completed } \\
\text { exams }\end{array}$ & $\begin{array}{l}\text { Average score: } \\
\text { completed } \\
\text { exams }\end{array}$ & $\begin{array}{l}\text { Average score: } \\
\text { completed } \\
\text { exams }\end{array}$ & $\begin{array}{l}\text { Average score: } \\
\text { completed } \\
\text { exams }\end{array}$ \\
\hline Overall smartphone use (OSU) & $-9.004^{*}(4.735)$ & $-1.105(1.226)$ & $-0.490^{* * *}(0.120)$ & $-0.499^{* *}(0.195)$ & $-0.127(0.286)$ & $-7.104(5.281)$ \\
\hline OSU $\times$ Female & $0.028(0.231)$ & & & & & $0.073(0.242)$ \\
\hline OSU $\times$ Age & $0.498^{*}(0.261)$ & & & & & $0.371(0.281)$ \\
\hline OSU $\times$ Foreign origin & $0.034(0.368)$ & & & & & $-0.067(0.386)$ \\
\hline OSU $\times$ Dutch is not main language at home & $-0.767(0.491)$ & & & & & $-0.694(0.516)$ \\
\hline \multicolumn{7}{|l|}{ OSU $\times$ Highest diploma father: no tertiary education (reference) } \\
\hline OSU $\times$ Highest diploma father: tertiary education outside college & $-0.296(0.283)$ & & & & & $-0.193(0.295)$ \\
\hline OSU $\times$ Highest diploma father: tertiary education in college & $-0.698^{* *}(0.273)$ & & & & & $-0.705^{* *}(0.285)$ \\
\hline OSU $\times$ At least one parent passed away & $0.567(0.968)$ & & & & & $0.897(0.993)$ \\
\hline OSU $\times$ Divorced parents & $-0.586^{* *}(0.281)$ & & & & & $-0.626^{* *}(0.292)$ \\
\hline \multicolumn{7}{|l|}{ OSU × Number of siblings: none (reference) } \\
\hline OSU × Number of siblings: one & $0.053(0.443)$ & & & & & $-0.236(0.470)$ \\
\hline OSU $\times$ Number of siblings: two & $0.293(0.463)$ & & & & & $0.123(0.481)$ \\
\hline OSU $\times$ Number of siblings: more than two & $0.094(0.526)$ & & & & & $0.028(0.553)$ \\
\hline OSU $\times$ In a relationship & $-0.438^{*}(0.258)$ & & & & & $-0.477^{*}(0.269)$ \\
\hline \multicolumn{7}{|l|}{ OSU × General health: (fairly) bad (reference) } \\
\hline OSU × General health: fairly good & & $1.178^{* *}(0.584)$ & & & & $1.272^{* *}(0.626)$ \\
\hline OSU $\times$ General health: very good & & $0.771(0.601)$ & & & & $0.993(0.645)$ \\
\hline OSU $\times$ Academic motivation scale & & $-0.007(0.167)$ & & & & $-0.012(0.173)$ \\
\hline OSU $\times$ Executive functioning problems scale & & $-0.176(0.250)$ & & & & $-0.167(0.257)$ \\
\hline OSU $\times$ Using laptop to take notes in class & & & $0.239(0.335)$ & & & $0.260(0.352)$ \\
\hline OSU $\times$ Living in a student room & & & & $-0.066(0.273)$ & & $0.082(0.288)$ \\
\hline OSU $\times$ Distance between home and university (in km) & & & & $0.002(0.005)$ & & $0.000(0.006)$ \\
\hline
\end{tabular}


OSU $\times$ Program in secondary education: Economics - languages/sports

OSU $\times$ Program in secondary education: Economics - maths

OSU $\times$ Program in secondary education: Ancient languages

OSU $\times$ Program in secondary education: Exact sciences - maths

OSU $\times$ Program in secondary education: other (reference)

OSU $\times$ General end marks in secondary education: less than $70 \%$

(reference)

OSU $\times$ General end marks in secondary education: between $70 \%$ and $80 \%$

\begin{tabular}{llllll}
\hline Additional control variables & All & All & All & All & All \\
\hline Number of observations & 696 & 696 & 696 & 696 & 696 \\
\hline \hline
\end{tabular}

Note. OLS stands for ordinary least squares. See Section 2.2 for a description of the data. The presented results are coefficient estimates, with standard errors in parentheses. ${ }^{* * *}(* *)((*))$ indicates significance at the $1 \%(5 \%)((10 \%))$ significance level. 